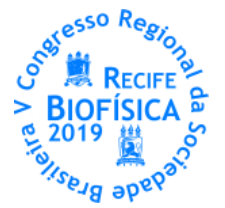

\title{
DESENVOLVIMENTO DE BIOSSENSOR POLIMÉRICO NANOESTRUTURADO PARA IDENTIFICAÇÃO DE INFECÇÕES BACTERIANAS
}

\author{
Jéssica M. Oliveira ${ }^{1 *}$, Isaac A. Morales ${ }^{1}$, Octavio L. Franco², Reginaldo G. Lima-Neto ${ }^{3}$, Maria D.L. Oliveira ${ }^{1}$, César A. \\ S. Andrade ${ }^{1}$
}

${ }^{1}$ Laboratório de Biodispositivos Nanoestruturados, UFPE; ${ }^{2}$ UCDB; ${ }^{3} \mathrm{UFPE}$

*jessicamariaal@hotmail.com

\section{INTRODUÇÃO}

As infecções bacterianas em seres humanos causam diversos sintomas, dentre os quais podemos destacar a febre, diarreia, vômito, choque séptico e coagulação vascular disseminada (Alexander e Rietschel, 2001). Além disso, doenças bacterianas como diarreia aviária e mastite bovina acometem animais da criação agropecuária nacional culminando na redução da qualidade das carnes e por fim, diminuição das vendas, implicando na redução da economia na área (Miranda, 2017). Devido a estes problemas, a aplicação de antibióticos é considerada a solução mais rentável. Infelizmente a exposição excessiva da flora bacteriana saudável ao tratamento com antibióticos promove o surgimento de bactérias resistentes aos antibióticos (Andreotti e Nicodemo, 2004). Existem diversos meios de detecção presuntiva para bactérias, dentre dos quais o crescimento em meios de cultura líquidos e sólidos, o uso da técnica ELISA e técnicas moleculares têm destaque (Jordana-Lluch et al., 2017; Takeo et al., 2017). No entanto, tais meios podem apresentar diversos vieses devido ao tempo de crescimento do microrganismo no meio de cultura (entre 24-72 horas), problemas de reações cruzadas nos métodos enzimáticos, e alto custo dos equipamentos e reagentes dos testes moleculares. Os biossensores são dispositivos de diagnóstico molecular que combinam a especificidade de uma sonda biológica com um método de transdução que converterá o reconhecimento biológico em um sinal analítico mensurável. Neste contexto, os métodos eletro analíticos, tais como a voltametria cíclica (VC) e a espectroscopia de impedância eletroquímica (EIE) fazem uso de propriedades elétricas mensuráveis (potencial, carga e corrente) e podem ser utilizadas para o estudo da interação entre biomoléculas e plataformas nanoestruturadas composta por nanomateriais, tais como as nanofibras, nanoestruturas de carbono e os polímeros conjugados (De Miranda et al.; Costa et al., 2017; Zanghelini et al., 2017); estes últimos com grande sensibilidade às mudanças de $\mathrm{pH}$. Por outro lado, os transdutores são construídos com um elemento sensor biológico ativo, que pode variar de fragmento de DNA, glicoproteína, proteína ou peptídeo o qual será responsável pela especificidade ao analito (De Miranda et al.). Alguns peptídeos fazem parte do sistema imune inato dos organismos vegetais e animais pelo que presentam características antimicrobianas. A seletividade destes peptídeos antimicrobianos (PAMs) e seu modo de ação singular tornou-os candidatos promissores para o desenvolvimento de novos agentes antibióticos que podem ser usados para superar o problema da resistência a antimicrobianos (Haney et al., 2017). Ademais, tais peptídeos têm a capacidade de assumir uma conformação anfipática de ligação a membranas celulares como são as bacterianas (Chung e Khanum, 2017). Na presente proposta propomos a encontrar soluções para este problema de saúde global associado com a crescente incidência de doenças infecciosas causadas por patógenos bacterianos pelo desenvolvimento de ferramentas de nova geração que possam aumentar drasticamente a eficiência do diagnóstico, assim como garantir amplo aceso para a população. Assim sendo, trabalharemos na miniaturização dos métodos de identificação de microrganismos empregando o uso de materiais nanoestruturados e os peptídeos antimicrobianos Mastoparano-L (Mast) e Indolicidina (Indo) com o propósito de integrar elementos sensores-atuadores e sistemas analíticos impedimétricos.

\section{MATERIAIS E MÉTODOS}

Polimerização da anilina e construção do biossensor:

O monômero de anilina foi diluído na proporção de $100 \mu \mathrm{L}$ para 20 $\mathrm{mL}$ de ácido clorídrico [0.5 M]. Posteriormente, a solução foi submetida a ultrassom para homogeneização da anilina no ácido. Em sequência, foi realizada a polimerização do monômero de anilina sobre o eletrodo de ouro através de voltametria cíclica. 0 gráfico apresentado na Fig. 1 exibe a média e o desvio padrão dos diferentes ciclos voltamétricos utilizados para formação do filme fino de polianilina (pani) sobre o eletrodo de trabalho.
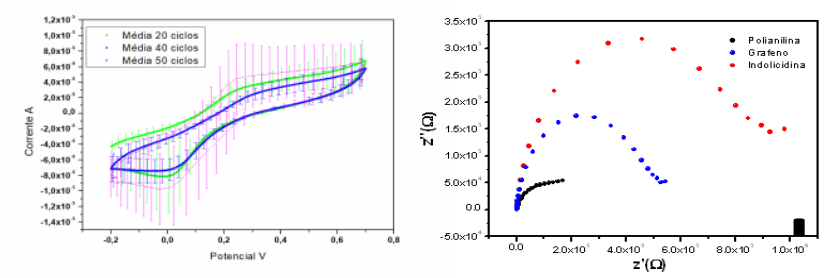

Figura 1. Voltamograma cíclico demonstrando a polimerização da anilina (A) e Diagrama de Nvquist referente a construção do biossensor (B) (Fonte: Autor).

A partir da Fig. 1a podemos observar uma menor variação na média de 40 ciclos, sendo portanto adotado 40 ciclos como o número de ciclos necessários para formar a camada ideal de polianilina. $\mathrm{Na}$ etapa seguinte, a solução de grafeno em acetona foi sonicada para permitir sua homogeneização e, posteriormente, $5 \mu \mathrm{L}$ foram depositados sobre o eletrodo modificado com polianilina. 0 grafeno foi modificado com grupos funcionais carboxílicos, os quais podem ser ativados quimicamente para promover sua interação com os grupos aminos livres do peptídeo antimicrobiano indolicidina. Os grupos funcionais foram ativados incubando 0 eletrodo pani/grafeno com $5 \mu \mathrm{L}$ da solução de EDC:NHS $(1: 1, v / v)$. Após a ativação do grafeno, foram aplicados $2 \mu \mathrm{L}$ [100 $\mu \mathrm{M}]$ de Indolicidina sobre a plataforma modificada, deixando o tempo de incubação de 10 min para permitir a interação das biomoléculas. Com a finalidade de calcular o limite de detecção do eletrodo foram 
testadas diluições seriadas de diferentes amostras bacterianas sobre o biossensor pani/grafeno/indolicidina.

A Fig. 1b apresenta os diagramas de Nyquist das diferentes camadas constituintes da plataforma biossensora. De acordo com o semicírculo de Cole-Cole em preto, a polianilina foi a camada que menor ofereceu resistência ao sistema. As cadeias poliméricas obtidas pela oxidação da anilina em presença de $\mathrm{HCl}$, se apresentaram no estado de oxidação esmeraldina. A polianilina esmeraldina apresenta condução eletrônica, o que justifica a baixa resistência a transferência de carga (Rct). 0 processo da interação pani/grafeno é demonstrado na curva em azul (Fig. 1b). 0 resultado da interação grafeno/indolicidina dá origem à última camada do biossensor, sendo demonstrado na curva impedimétrica em vermelho. Finalmente, a plataforma biossensora foi testada com amostras de bactérias patogênicas.

\section{Teste do biossensor frente a diferentes amostras bacterianas:}

A indolicidina é um peptídeo curto e hidrofóbico, constituído por 13 resíduos de aminoácidos que apresentam a seguinte sequência: ILPWKWPWWPWRR-NH2. A indolicidina é um peptídeo catiônico que apresenta afinidade pelas regiões aniônicas presentes na membrana bacteriana. 0 resultado da interação indolicidina/membrana bacteriana produz uma resposta elétrica mensurável.

Foram testadas diluições seriadas de diferentes amostras bacterianas contra a plataforma biossensora, para avaliar a sua sensibilidade e o limite de detecção. Antes da realização da análise por EIE, os eletrodos contendo a plataforma biossensora foram incubados por 10 min para cada concentração testada, sendo a concentração inicial de [1.000.000 UFC /ml].
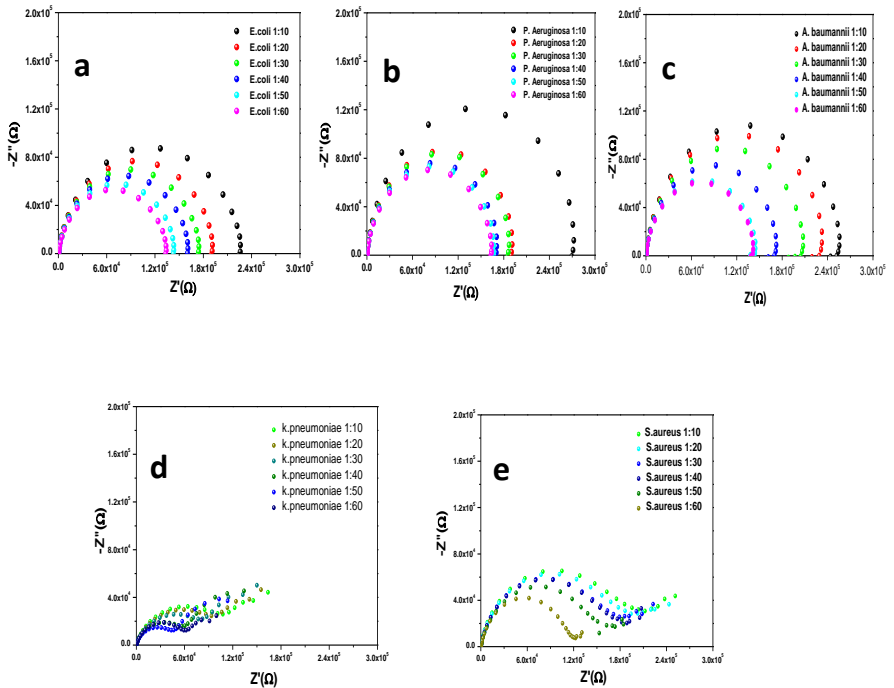

Figura 2. Diagrama de Nyquist da resposta do sensor frente a diferentes espécies bacterianas (Fonte: Autor).

Na Fig. 2a apresentamos o diagrama de Nyquist correspondente à diluição seriada da amostra de E. coli sobre o biossensor. É possível notar um incremento no Rct proporcional à concentração de bactérias, indicando que a plataforma biossensora está interagindo com a amostra bacteriana. Na Fig. $2 \mathrm{~b}$ é apresentada a resposta do sensor frente a diferentes concentrações da bactéria $P$. aeruginosa. É possível notar que a impedância aumenta à medida que se eleva a concentração de bactérias na superfície. A resposta da indolicidina frente a diferentes concentrações da bactéria A.baumannii pode ser visualizada na Fig. 2c. A resposta impedimétrica foi proporcional a concentração de A.baumannii, K.pneumoniae (Fig. 2d) e S.aureus (Fig. 2e).

Com exceção da espécie Staphylococcus aureus, todas as bactérias testadas são Gram negativas. Os peptídeos antimicrobianos atuam junto às bactérias através de um mecanismo de dois passos associado às interações eletrostáticas e hidrofóbicas. Por apresentar características hidrofóbicas possui grande afinidade pelas membranas bacterianas ricas em estruturas lipídicas, como é o caso das bactérias Gram negativas de modo geral.

\section{RESULTADOS E DISCUSSÃO}

$\mathrm{Na}$ Fig. 3 é apresentado o ajuste linear da resposta do sensor em função da concentração de bactérias. Cumpre salientar que quanto mais próximo de 10 valor de $\mathrm{R}^{2}$, maior será o nível de correlação entre os pontos. A partir do ajuste linear é possível obter a equação da reta a fim de estimar o número de unidades formadoras de colônia em amostras desconhecidas.
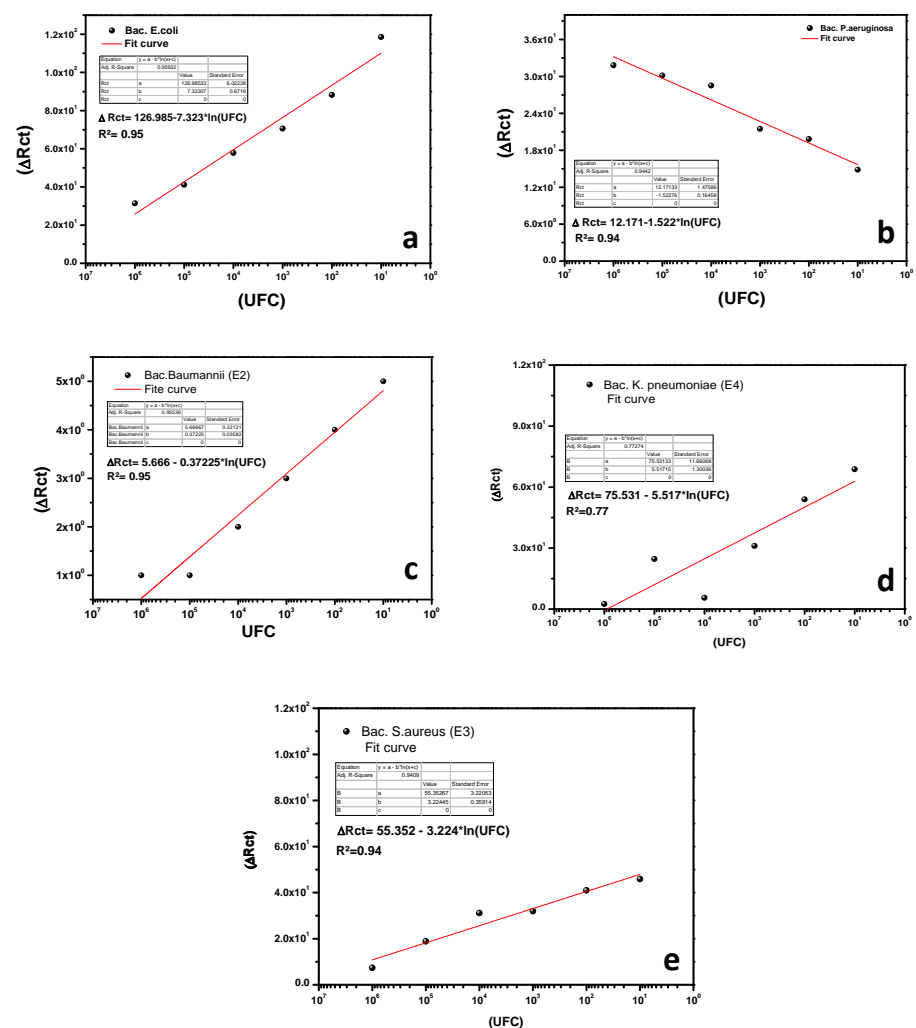

Figura 3. Curvas de calibração de diferentes espécies bacterianas (Fonte: Autor).

\section{CONCLUSÕES}

Demonstramos o desenvolvimento de um sensor baseado em peptídeos muito sensível que pode ser útil para detectar a presença de microrganismos infecciosos pertencentes a um amplo espectro de espécies de bactérias patogênicas. Foi obtido um limite baixo de resposta do biossensor polimérico e peptídeo na detecção de diversas bactérias. Portanto, foi desenvolvido um sistema simples para detectar e identificar patógenos quando comparado a procedimentos complexos tradicionais.

\section{REFERÊNCIAS}

ALEXANDER, Christian; RIETSCHEL, Ernst Th. Invited review: bacterial lipopolysaccharides and innate immunity. Journal of endotoxin research, v. 7, n. 3, p. 167-202, 2001.

BORÉM, Aluízio; MIRANDA, Glauco Vieira; FRITSCHE-NETO, Roberto. Melhoramento de plantas. 2017. 
ANDREOTTI, Renato; NICODEMO, Maria Luiza Franceschi. Uso de antimicrobianos na produção de bovinos e desenvolvimento de resistência. Campo Grande: Embrapa Gado de Corte, 2004.

JORDANA-LLUCH, Elena et al. Molecular diagnosis of bloodstream infections in onco-haematology patients with PCR/ESI-MS technology. Journal of Infection, v. 74, n. 2, p. 187-194, 2017.

DE MIRANDA, Juliana L. et al. A simple nanostructured biosensor based on clavanin A antimicrobial peptide for gram-negative bacteria detection. Biochemical engineering journal, v. 124, p. 108-114, 2017.

HANEY, Evan F .; MANSOUR, Sarah C .; HANCOCK, Robert EW. Peptídeos antimicrobianos: uma introdução. Em: Peptídeos Antimicrobianos . Humana Press, Nova lorque, NY, 2017. p. 3-22.

CHUNG, Pooi Yin; KHANUM, Ramona. Antimicrobial peptides as potential anti-biofilm agents against multidrug-resistant bacteria. Journal of Microbiology, Immunology and Infection, v. 50, n. 4, p. 405-410, 2017. 